đào tạo về kỹ năng giao tiếp với nhóm chưa được đào tạo.

\section{TÀI LIÊU THAM KHẢO}

1. Nguyễn Ngọc Huyên (2019). Sự tự tin trong thực hành kỹ năng lâm sàng của sinh viên điêu dưỡng chính quy tại Bệnh viện trung ương Thái Nguyên năm 2019. Ṫạp chí Khơa học và công nghế Đại học Thái Nguyên, 225(01), 47-52.

2. Lương Ngọc Khuê (2012). Tăng cường năng lực quản lý điêu dưỡng. Bộ Y Tế.

3. Nguyến Thúy Ly, Yvonne Osborne và Patsty Yates (2014). Kiến thức, thái độ và sự tự tin trong thực hanh chăm sóc giảm nhẹ của điêu dưỡng tại một số bệnh viện chuyên khoa Ung bướu Hà Nôii. International journal of palliative nursing, 20(9), 448.

4. Bandura A (1977). Self-confidence: toward a unifying theory of behavioral change. Psychological Review, 84(2), 191

5. Chia-Hui W, Kathryn A, Nai-Wen K (2016). The Role of Head Nurse on Communication: A
Social Network Approach. International Journal of Future Computer and Communication, Vol. 5, No. 1, February 2016.

6. Ika C, Novieastari E, Nuraini T (2019). The role of a head nurses in preventing interdisciplinary conflicts. Enferm Clin; 29(S2): 123-127.

7. Margaret Rosenzweig et all (2008). Patient communication simulation laboratory for students in an acute care nurse practitioner program. American Journal Of Critical Care, 17(4), 364-372.

8. Mark D. Hecimovich, MSc, DC, ATC and Simone E. Volet, PhD (2009), Importance of Building Confidence in Patient Communication and Clinical Skills Among Chiropractic Students. The Journal of Chiropractic Education; 23(2): 151-164.

9. Mojtaba Fattahi Ardakani, Mohammad Ali Morowati Sharifabad, Mohammad Amin Bahrami, Amin Salehi Abargouei4 (2019). The effect of communication skills training on the self-confidence of nurses: a systematic review and meta-analysis study. Bali Medical Journal, 8(1), 144-152. P-ISSN.2089-1180, E-ISSN.2302-2914 144

\title{
KHẢO SÁT VIÊC SỬ DỰG THUỐC GIẢM ĐAU VÀ NHỮNG RÀO CẢN TRONG QUẢN LÝ ĐAU UNG THƯ TRÊN BỆNH NHÂN ĐIỀU TR! TẠI BỆNH VIỆN K2
}

\section{Bùi Thanh Loan', Đoàn Lực ${ }^{2}$ Phan Thị Quỳnh Nga ${ }^{3}$, Quách Phụng Linh ${ }^{3}$, Nguyễn Tứ Sơn ${ }^{1}$ \\ nhân trong quản lý đau ung thư bao gồm: không nắm được hướng dẫn dùng thuốc, quan niệm rằng thuốc giảm đau chỉ nên uống khi đau, cố gắng chịu đau, sợ tác dụng phụ và sợ dung nạp thuốc. Cần can thiệp để cải thiện vấn đề tuân thủ dùng thuốc và hạn chế các rào cản từ bệnh nhân trong quản lý đau ung thư.}

\section{TÓM TẮT}

Mục tiêu: Khảo sát việc kê đơn sử dụng thuốc giảm đau, sự tuân thủ dùng thuốc giảm đau và những rào cản trên bệnh nhân trong quản lý đau ung thư. Phương pháp: Nghiên cứu cắt ngang, sử dung bố câu hỏi thông qua hình thức phỏng vấn trực tiểp hoặc qua điên thoai. Kết quả: Tuổi trung bình của 46 bênh nhân là 57,5 ; ung thư phế quản phổi là loại ung thư phổ biến nhất. Phần lớn bênh nhân còn đau mức độ trung bình $(63 \%)$ và nặng $(21,7 \%)$. Phác đồ giảm đau phổ biến nhất được duy trì là tramadol + paracetamol. Tỷ lệ không tuân thủ dùng thuốc giảm đau là $65,2 \% ; 19,6 \%$ bệnh nhân không mô tả đúng hướng dẫn dùng thuốc của cán bộ y tế.Từ 47,5\% đến 100\% bệnh nhân đồng ý hoàn toàn với các vấn đề: như thuốc giảm đau chỉ nên dùng khi đau, đau là diến biến tự nhiên của bệnh cân phải chịu đựng, sợ tác dụng phụ và sợ thuốc giảm đau sẽ mất dần tác dụng. Kết luận: Gần $2 / 3$ bệnh nhân không tuân thủ việc sử dụng thuốc giảm đau; những rào cản chính từ bệnh

\footnotetext{
${ }^{1}$ Trường Đại hoc Dước Hà Nôii

${ }^{2}$ Trung tâm Chăm Sóc Giảm Nhẹ, Bệnh viện K ${ }^{3}$ Bênh viênK

Chịu trách nhiệm chính: Bùi Thanh Loan

Email: buithanhloandkh@gmail.com

Ngày nhận bài: 9.8.2021

Ngày phản biên khoa hoc: 4.10 .2021

Ngày duyệt bài: 14.10.2021
}

Tư khóa: Quản lý đau ung thư, rào cản, tuân thủ điều trị, bệnh viện $\mathrm{K}$.

\section{SUMMARY \\ THE USE OF ANALGESICS AND BARRIERS TO CANCER PAIN MANAGEMENT IN K2 HOSPITAL}

Objectives: To investigate analgesic prescribing, pain medication adherence and patient barriers to cancer pain management. Methods: Across-sectional studywas conducted, patients wereface-to-face interviewedor via telephonewith a questionnaire. Results: 46 patientsparticipated the study (mean age: 57.5). Lungcancer wasthe most common cancer. Most patients weresuffering moderate pain $(63 \%)$ and severe pain $(21.7 \%)$. The most common analgesic regimen was tramadol+paracetamol. The rate of patients not adherenceis $65.2 \% ; 19.6 \%$ of patients did not know the instructions of using analgesics. From $47.5 \%$ to $100 \%$ of patients agree with issues such as pain medication should only be used when pain, pain is a natural course of the disease that must be endured, fear of side effects and fear of pain medication will gradually lose its effect. Conclusion: 
Nearly two-third of patients in the study did not adhere with the use of analgesics; and major patient barriers to cancer pain management include: failure to understand dosing instructions, the notion that pain medications should only be taken when in pain, endure the pain without treatment, fear of side effects, and fear of tolerance. Interventions are needed to improve medication adherence and reduce barriers to cancer pain management.

Key words: Cancer pain management, barriers, adherence, $\mathrm{K}$ hospital.

\section{I. ĐẶT VẤN ĐỀ}

Đau là một trong những triệu chứng phổ biến và đáng sợ nhất xảy ra ở bệnh nhân ung thư, gây ảnh hưởng nghiêm trọng đến chất lượng cuộc sống và là một yếu tố dự báo khả nẳng sống của bệnh nhẩn[5]. Vì vậy, giảm đau đã được xác định là một trong những nhiệm vụ quan trong nhất trong điêu trị. Mặc dù đã có nhiều bằng chứng về hiệu quả giảm đau, một lượng lớn bệnh nhân ung thư trên thế giới vẫn chưa được giảm đau đầy đủ. Đồng thời, thiếu tuân thủ điều trịlà một trong những nguyên nhân quan trọng dẫn đên thất bại hoặc không đạt mục tiêu quản lý đau. Nguyên nhân không tuẩn thủ sử dụng thuốc giảm đau đến từ những rào cản trong quản lý đau của bệnh nhân như sợ nghiện thuốc, lo ngại về tác dụng phụ, lo ngại về sự dung nạp thuốc,... Nhằm có cái nhìn về sử dụng thuốc giảm đau và rào cản trong quản lý đau ung thư', nghiên cứu được tiến hành với mục tiêu khảo sát việc kê đơn thuốc giảm đau, tuẩn thủ dùng thuốcvà những rào cản của bệnh nhân trong quản lý đau ung thư đang điều trị tại Trung tâm Chăm Sóc Giảm Nhẹ - Bệnh viện K.

\section{II. ĐỐI TƯợNG VÀ PHƯƠ'NG PHÁP NGHIÊN CỨU}

Đối tượng nghiên cứu: Bệnh nhânung thư từ 18 tuổi trở lên nhập viện điêuu trị hoặc các bệnh nhân ngoại trú tái khám tại Trung tâm Chăm Sóc Giảm Nhe - Bệnh viện K trong khoảng thời gian 1/4/2021 đến 15/9/2021 đông ý tham gia nghiên cứu. Tiêu chuẩn lựa chọn là các bệnh nhân có đau liên quan đên ung thư và đã được kê đơn điêu trị đau bằng bất kỳ 1 loại thuốc giảm đau nào trong vòng ít nhất 7 ngày. Loại trừ các bệnh nhân suy giảm nhận thức, bệnh nhân không thể giao tiếp bằng î̛̀i, các bệnh nhân đang gặp tình trạng cấp cứu, bệnh nhân mới phẫu thuật trong vòng 1 tháng trước đó.

\section{Phương pháp nghiên cứu:}

* Thiết kế nghiên cứu: Nghiên cứucắt ngang

* Thu thập số liệu: Các bệnh nhân được phỏng vẫn trực tiếp hoặc qua điện thoại sử dụng bộ câuu hỏi và hồi cứu dữ liệu từ hồ sơ bệnh án của bệnh nhân lưu tại bệnh viện $\mathrm{K}$.
* Công cụ phỏng vấn là bộ câu hỏi do nhóm nghiên cứu thiết kế. Trong đó, đánh giá đau dựa trên công cụ đánh giá đau BPI được trích từ tài liệu "Hướng dẫn chăm sóc giảm nhẹ đôii với người bệnh ung thư và AIDS" - Bộ Y Tế (2006)[1]. Bộ câuu hỏi phỏng vấn rào cản của bệnh nhân được thiết kế dựa trên các rào cản đã được công bố trong các nghiên cứu tương tự.

* Quy ước trong nghiên cứu:

- Mức độ đau của bệnh nhân được xác định dựa trên điểm đau nă̆ng nhất trong 24 giờ trước với quy ướctheo hướng dẫn của NCCN - 2020 (National Comprehensive Cancer Network) [3]:

- Đau nhe: điểm đau từ 1-3

- Đau trung bình: điểm đau từ 4-7

- Đau nặng: điểm đau 8-10

- Liều lượng thuốc giảm đau được tra cứu theo hướng dẩn giảm đau trong ung thư của WHO (2018) và NCCN $(2020)[3,6]$.

- Bệnh nhân được xác định biết cách dùng thuốc đúng nếu mồ tả đúng hướng dẫn trong đơn thuốc của Bác sĩ khi được đề nghị mô tả lại cách dùng thuốc cán bộ y tễ đã hướng dẫn họ.

- Bệnh nhân được xác định không tuân thủ dùng thuốc giảm đau nếu cách dùng thuốc của họ khác với hướng dẫn được Bác sĩ kê đơn.

* Xứ lý số liệu: Số liệu được xử lý bằng Excel 2016 và R 3.6.3

\section{KẾT QUẢ NGHIÊN CỨU}

Đặc điểm mẫu nghiên cứu. Tổng số 46 bệnh nhân đủ tiêu chuẩn đồng ý ý tham gia nghiên cứu. Tuổi trung bình của mẫu nghiên cứu là 57,5 , tỷ lệ nam chiểm $69,6 \%$ gấp hơn 2 lần so với nữ 30,4\%. Gần một nửa mấu nghiên cứu là các bệnh nhân ung thư phế quản - phổi $(45,7 \%)$, tiếp theo sau là các loại ung thư thực quản $10,9 \%$, ung thư vú $6,3 \%$, các loại ung thư khác chiếm tỷ lệ < $5 \%$ gồm: ung thư dạ dày, trực tràng, hạ hầu, cổ tử cung, tiên liệt tuyễn, buồng trứng, gan, đại tràng, cột sống, lách, khẩu cái, ống tai ngoài, lympho. Phần lớn bệnh nhân ung thư giai đoạn 4 (91,3\%); 82,6\% bệnh nhân có di căn; 41,3\% mẫu nghiên cứu đang điều trị ung thư bằng biện pháp hóa trị. Sau khi điều trị bằng phác đồ giảm đau ít nhất 7 ngày mức độ đau của bệnh nhân trong mẫu nghiên cứu ghi nhận được gồm đau nặng $21,7 \%$, đau trung bình $63 \%$, đau nhe $15,2 \%$.

Các phác đồ giảm đau được kê đơn. Phác đồ được sử dụng phổ biến nhất trong nghiên cứu là Tramadol + paracetamol \pm thuốc hố trợ giảm đau (64,7\%).Trong đó, 15,2\% bệnh nhân đau nặng đang được duy trì với phác đồ này. Các opioid mạnh như morphin, fentanyl đang 
được sử dụng duy trì cho 4 (8,8\%) bệnh nhân.

Tất cả các thuốc giảm đau và hỗ trợ giảm đau đều được sử dụng với chế độ liều trong giới hạn cho phép.

\section{Bảng 1. Các phác đồ giảm đau bệnh nhân đang duy trì}

\begin{tabular}{|c|c|c|c|c|c|c|}
\hline \multirow[b]{2}{*}{$\begin{array}{l}\text { Mứrc độ } \\
\text { đau }\end{array}$} & \multicolumn{6}{|c|}{ Các phác đồ giảm đau, $\mathrm{N}=46, \mathrm{n}(\%)$} \\
\hline & $\begin{array}{c}\text { Tramadol }+ \\
\text { paracetamol } \\
\underset{\text { THTGE }^{*}}{ }\end{array}$ & $\begin{array}{c}\text { Codein }+ \\
\text { paracetamol } \pm \\
\text { THTGE* }^{*}\end{array}$ & $\begin{array}{c}\text { Tramadol }+ \\
\text { paracetamol }+ \\
\text { diclofenac } \pm \\
\text { THTGĐ* }^{*}\end{array}$ & $\begin{array}{l}\text { Morphin } \pm \\
\text { THTGĐ* }^{*}\end{array}$ & $\begin{array}{c}\text { Morphin+ } \\
\text { paracetamol }+ \\
\text { tramadol } \pm \\
\text { THTGE* }^{*}\end{array}$ & $\begin{array}{c}\text { Fentanyl }+ \\
\text { morphin }+ \\
\text { codein }+ \\
\text { ibuprofen }+ \\
\text { paracetamol }+ \\
\text { THTGĐ }\end{array}$ \\
\hline Đau nhẹ & $4(8,7 \%)$ & $3(6,5 \%)$ & $0(0 \%)$ & $0(0 \%)$ & $0(0 \%)$ & $0(0 \%)$ \\
\hline $\begin{array}{l}\text { Dau trung } \\
\text { bình }\end{array}$ & $20(43,5 \%)$ & $7(15,2 \%)$ & $1(2,2 \%)$ & $1(2,2 \%)$ & $0(0 \%)$ & $0(0 \%)$ \\
\hline Đau nă̆ng & $7(15,2 \%)$ & $0(0 \%)$ & $0(0 \%)$ & $1(2,2 \%)$ & $1(2,2 \%)$ & $1(2,2 \%)$ \\
\hline Tống số (46) & $31(64,7 \%)$ & $10(21,7 \%)$ & $1(2,2 \%)$ & $2(4,4 \%)$ & $1(2,2 \%)$ & $1(2,2 \%)$ \\
\hline
\end{tabular}

*THTGĐ: Thuốc hỗ trợ giảm đau

Tuân thủ dùng thuốc giảm đau và hỗ trợ giảm đau. Có $65,2 \%$ bệnh nhân không tuân thủ việc sử dụng phác đồ giảm đau như được kê đớn. Trong đó, phổ biến nhất là các bệnh nhân thay đổi liều chiếm 37,0\%. Có 15,2\% bệnh nhân chỉ dùng thuốc khi đau nhiều; $15,2 \%$ bệnh nhân có dùng thêm các thuốc giảm đau khác, 10,9\% bênh nhân bỏ hoàn toàn thuốc giảm đau mặc dù vẩn còn đau.

Bảng 3. Tuân thủ dùng thuốc giảm đau và hố trợ giảm đau

\begin{tabular}{|c|c|}
\hline Tiêu chí & $\begin{array}{c}\text { Số beênh } \mathbf{n h a ̂ n} \\
(\mathbf{n}, \mathbf{\%}) \mathbf{N}=\mathbf{4 6}\end{array}$ \\
\hline Tuân thủ dùng thuốc giảm đau & $16(34,8 \%)$ \\
\hline $\begin{array}{c}\text { Không tuân thủ dùng thuốc } \\
\text { giảm đau }\end{array}$ & $30(65,2 \%)$ \\
\hline - Thay đối liều & $17(37,0 \%)$ \\
\hline - Chỉ dùng khi đau & $7(15,2 \%)$ \\
\hline - Thêm thuốc & $7(15,2 \%)$ \\
\hline - Bỏ hoàn toàn & $5(10,9 \%)$ \\
\hline - Chì dùng thuốc hồ trợ & $1(2,2 \%)$ \\
\hline
\end{tabular}

\section{giảm đau}

- Bớt thuốc giảm đau $1(2,2 \%)$

Những rào cản trong quản lý đau ung thư ở bềnh nhân. Có $19,6 \%$ bênh nhân đã không mồ tả đúng cách dùng thuốc được cán bộ y tế hướng dẫn và tất cả các bệnh nhân này đều sử dung thuốc với chế đô liều khác với đơn kê. Đáng chú ý, hầu hết các bênh nhân đồng ý rằng thuốc giảm đau chỉ nên dùng khi đau, không nên dùng liên tục kể cả khi có đau (100\%) và đau là diễn biến tự nhiên của bệnh cần phải chịu đựng (90\%). Khoảng một nửa số bệnh nhân đồng ý về các rào cản như sợ tác dụng phụ của thuốc $(62,5 \%)$, sợ dung nạp thuốc $(47,5 \%)$, quan niệm rằng đau tằng lên là bệnh tình nặng hơn $(50 \%)$. Sợ nghiện thuốc giảm đau, hoài nghi về tác dụng của thuốc, mong muốn trở thành "bệnh nhân tốt" ít phàn nàn về đau và sợ bác sĩ phân tâm viêc điều trị khối u không phải là những rào cản chính được xác định trong nghiên cứu.

Bảng 3. Những rào cản trong quản lý đau ung thư ở bệnh nhân

\begin{tabular}{|c|c|c|c|}
\hline Tiêu chí & \multicolumn{3}{|c|}{ Số bệnh nhân n (\%) } \\
\hline Mô tả cách dùng các thuốc được kê đơn, N=46 & $\frac{\text { Mô tả đúng }}{37(80,4 \%)}$ & \begin{tabular}{r|r} 
& Không n \\
$9(1$
\end{tabular} & 1ô tả đúng \\
\hline Các rào cản, $\mathbf{N}=40$ & Đồng ý & $\begin{array}{l}\text { Không chắc } \\
\text { chắn }\end{array}$ & $\begin{array}{l}\text { Không } \\
\text { đồng ý }\end{array}$ \\
\hline $\begin{array}{l}\text { Thuốc giảm đauchỉ nên uống khi đau, không nên dùng } \\
\text { liên tục kể cả khi có đau }\end{array}$ & $40(100 \%)$ & $0(0 \%)$ & $0(0 \%)$ \\
\hline Đau là diễn biến tự nhiên của bệnh cần phải chịu đựng & $36(90 \%)$ & $0(0 \%)$ & $4(10 \%)$ \\
\hline Ōng/bà lo lắng về tác dung phụ của thuốc & $25(62,5 \%)$ & $4(10 \%)$ & $11(27,5 \%)$ \\
\hline Lo lắng rằng đau tăng lên là bệnh đang nặng hơn & $20(50 \%)$ & $9(22,5 \%)$ & $11(27,5 \%)$ \\
\hline $\begin{array}{c}\text { Ông/bà lo lắng thuốc giảm đau sẽ giảm dần tác dụng } \\
\text { nên để dành để dùng khi bệnh nặng hơn }\end{array}$ & $19(47,5 \%)$ & $14(35 \%)$ & $7(17,5 \%)$ \\
\hline Ông/bà sợ nghiện thi & $12(30 \%)$ & $9(22,5 \%)$ & $19(47,5 \%)$ \\
\hline Thuốc giảm đau không thực sư giải quyết & $5(12,5 \%)$ & $9(22,5 \%)$ & $26(65 \%)$ \\
\hline
\end{tabular}




\begin{tabular}{|c|c|c|c|}
\hline có dùng thuốc cơn đau cũng không hết & & & \\
\hline Lo ngại bác sĩ cảm thấy phiền khi phản hồi về đau & $3(7,5 \%)$ & $4(10 \%)$ & $33(82,5 \%)$ \\
\hline $\begin{array}{c}\text { Sợ bác sĩ phân tâm việc điều trị khối u của mình nễu } \\
\text { phàn nàn nhiều về cơn đau }\end{array}$ & $1(2,5 \%)$ & $\mathbf{3}(10 \%)$ & $35(87,5 \%)$ \\
\hline
\end{tabular}

\section{BÀN LUẬN}

\section{Việc sử dụng thuốc giảm đau trong quản}

lý đau ung thư. Bệnh nhân trong nghiên cứu được kê đớn đa dạng các thuốc giảm đau trong các nhóm thuốc được khuyến cáo bởi Bộ Y tế và Tổ chức Y tế Thế giới. Nguyên tắc phối hợp các thuốc giảm đau đa mô thức cũng được thể hiện trong các phác đồ bao gồm: phối hợp các nonopioid, non-opioid với opioid, kết hợp với các thuốc hỗ trợ giảm đau. Việc phối hợp thuốc giúp tăng hiệu quả và giảm tác dụng bất lợi từng nhóm thuốc.

Về mối liên hệ giữa phác đồ giảm đau và mức độ đau, phần lớn bệnh nhân đang được duy trì với phác đồ giảm đau bậc 2 , trong đó các thuốc giảm đau non-opioid và opioid yếu thường được phối hợp trong 1 biệt dược. Theo hướng dần của Bộ Y Tế - 2006, việc sứ dụng thuốc giảm đau nển tuân theo thang giảm đau 3 bậc với đau mức độ nặng nên sử dụng phác đồ giảm đau bậc 3 (opioid mạnh \pm non-opioid). Tuy vậy, trong nghiên cứu, 15,2\% bệnh nhân đau mức độ nặng đang được duy trì với phác đồ giảm đau bậc 2.Phác đồ này có thể chưa phù hợp với mức độ đau của họ[1]. Theo hướng dẫn của WHO, các bệnh nhân đau từ mức độ trung bình đến nặng nển được điều trị đau với opioid trong đó nên ưu tiên morphin đường uống [6]. Kết quả thử nghiệm lâm sàng so sánh 2 liệu pháp điều trị morphin liều thấp với opioid yếu ở bệnh nhân có mức độ đau trung bình cho thấy nhóm sử dụng morphin cho hiệu quả điều trị tốt hơn, nhanh hơn, điểm tổng thể tình trạng của bệnh nhân cải thiện hơn. Trong khi đó, tần suất tác dụng phụ của hai nhóm là tương đương và nhóm sử dụng opioid yếu đòi hỏi thay đổi phương pháp điều trị thường xuyên hơn vì giảm đau không đầy đủ.Vì vậy,morphin cũng có thể được cân nhắc như một lựa chọn tiêu chuẩn cho bệnh nhân đau mức độ trung bình, đặc biệt là khi lựa chọn giảm đau ban đầu[2]. Ngoài ra, cũng theo khuyến cáo của WHO, các công thức bào chế kết hợp của thuốc giảm đau non-opioid và opioid không được khuyến khích vì làm mất khả năng hiệu chỉnhmỗi loại thuốc và nguy cơ phơi nhiểm với liều cao tiềm năng độc tính của các non-opioid.Do đó, việc sử dụng rộng rãi các biệt dược phối hợp nên được cân nhắc thêm[6].

Liên quan đến khía cạnh tuân thủ dùng thuốc giảm đau, gần 2/3 số bệnh nhân đã không tuân thủ việc sử dụng thuốc so với đơn kê.Khi so sánh với các nghiên cứu tương tự trên thế giới, tỷ lệ tuân thủ dùng thuốc ghi nhận được dao động khá lớn từ 20-95\%[4]. Tỷ lệ lớn bệnh nhân không tuân thủ là lý do quan trọng dẫn đến hầu hết các bệnh nhân còn đau mức độ trung bình thậm chí đau nặng sau điều trị. Gần $1 / 5$ số bệnh nhân không mổ tả được đúng hướng dẫn dùng thuốc. Trên thực tế, cán bộ y tế thường hướng dẫn trực tiếp cho bệnh nhân hoặc người nhà của họ cách thức sử dụng thuốc.Tuy nhiên, môt bểnh nhân có thể có nhiều người chăm sóc dấn đến sự sai lệch thông tin khi truyền tải giữa những người chăm sóc và bệnh nhân.Thậm chí một số bệnh nhân không được người nhà hướng dấn lại cá́ch dùng thuốc. Đặc biệt,mặc dù được hướng dẫn, bệnh nhân vẫntự ý sử dụng theo cách khác dẫn đến dùng sai chế độ liều hoặc bệnh nhân không dùng thuốc mà cổ gắng chịu đau.Ngoài ra, dạng morphin được kê đơn là viền nang morphin $30 \mathrm{mg}$, tuy nhiên liều sử dụng được kê đơn mỗi lần có thể nhỏ hơn và bệnh nhẩn cần pha một viên thuốc chia thành nhiều liều. Một số bệnh nhân cảm thấy bất tiện với cách dùng thuốc này dẫn đến việc họ uống nguyên viên và giãn khoảng cách dùng thuốc.

Những rào cản trong quản lý đau từ bệnh nhân. Những rào cản chính của bệnh nhân được xác định trong nghiên cứu khá tương đồng với các rào cản chính được xác định trong các nghiên cứu tại các nước châu Á bao gồm: niềm tin rằng thuốc giảm đau chỉ nên được dùng khi đau, cố gắng chịu đau, sợ tác dụng phụ của thuốc, sợ dung nap thuốc $[4,7]$. Đau vốn dĩ là một triệu chứng chủ quan và trong các loại đau thồng thường, thuốc giảm đau chỉ nên được sử dụng khi đau. Tuy nhiên điều trị đau ung thư có những điểm khác biệt, một trong các nguyên tắc quan trọng được hướng dẫn bởi WHO là thuốc giảm đau cần được đưa theo lịch trình cố định để đảm bảo liều tiếp theo được sử dụng trước khi liều phía trước hết tác dụng nhằm duy trì tác dụng giảm đau liên tục [6]. Bên cạnh đó, một số bệnh nhân lo sợ tác dụng phụ của thuốc giảm đau nên hạn chế tối đa việc sử dụng hoặc thậm chí bỏ thuốc hoặc thay thế bằng các loại thuốc khác, bệnh nhân tinrằng thuốc giảm đau sẽ giảm dần tác dụng nên cần phải được sử dụng tiết kiệm phòng khi đau nặng hơn. Tất cả các rào cản 
này có thể là lý do khiến bệnh nhân giảm liều, bớt thuốc, bỏ thuốc và chỉ dùng thuốc khi quá đau qua đó giảm hiệu quả giảm đau.

\section{KẾT LUẦN}

Nghiên cứu đã ghi nhận môt lượng nhỏ bệnh nhân chưa được sử dụng thuốc giảm đau tương xứng với mức độ đau. Tỷ lê không tuân thủ sử dụng thuốc cao và những rào cản chính từ phía bệnh nhân trong quản lý đau ung thư. Các kết quả này là cơ sở cho việc xây dựng một số biện pháp, đặc biệt là các vẩn đề cần can thiệp giáo dụcbệnh nhân nhằm tăng cường hiệu quả giảm đau ung thư.

\section{TÀI LIỆU THAM KHẢO}

1. Bô Y Tế (2006), Hướng dẫn chăm sóc giảm nhe đổi với người bệnh ung thư và AIDS, Nhà xuất bản Y học, Hà Nội, pp.

2. Bandieri E., Romero M., Ripamonti C. I., Artioli F., Sichetti D., Fanizza C., Santini D., Cavanna L., Melotti B., Conte P. F., Roila F., Cascinu S., Bruera E., Tognoni G., Luppi M.
(2016), "Randomized Trial of Low-Dose Morphine Versus Weak Opioids in Moderate Cancer Pain", J Clin Oncol, 34(5), pp. 436-42.

3. National Comprehensive Cancer Network (2020), Adult cancer pain, pp.

4. Oldenmenger $W H$, Sillevis Smitt $P A$, van Dooren S, Stoter G, CC van der Rijt (2009), "A systematic review on barriers hindering adequate cancer pain management and interventions to reduce them: a critical appraisal", Eur J Cancer, 45(8), pp. 1370-1380.

5. Van den Beuken-van Everdingen $\mathbf{M H}_{\text {, }}$ Hochstenbach LM, Joosten EA, Tjan-Heijnen VC, DJ Janssen (2016), "Update on Prevalence of Pain in Patients With Cancer: Systematic Review and Meta-Analysis", J Pain Symptom Manage, 51(6), pp. 1070-1090.

6. World Health Organization (2018), WHO guidelines for the pharmacological and radiotherapeutic management of cancer pain in adults and adolescents, $\mathrm{pp}$.

7. Xu X., Luckett T., Wang A. Y., Lovell M., Phillips J. L. (2018), "Cancer pain management needs and perspectives of patients from Chinese backgrounds: a systematic review of the Chinese and English literature", Palliat Support Care, 16(6), pp. 785-799.

\section{ĐÁNH GIÁ TRÌNH TRANG NẢY CHỒI U TRONG UNG THƯ VÚ THỂ ỐNG XÂM NHẬP BẰNG GIẢI PHẪU BỆNH KỸ THUÂTT Số}

\section{TÓM TẮT}

Trong ung thư biểu mô (UTBM) tuyến vú xâm nhập, NCU độ cao tương quan với kích thước u lớn, xâm nhập mạch, di căn hạch và giảm tỷ lệ sống 5 năm của bệnh nhẩn ung thư vú. Mục tiêu: (1) Xác định tỷ lệ các mức độ nảy chồi u trong ung thư biểu mô tuyến vú thể ống xâm nhâp. (2) Nhân xét môt số mối liên quân giữa các mức nảy chồi u với các đặc điểm giải phẫu bênh. Đối tượng và phương pháp nghiên cứu: Mẫu mô u của 232 bệnh nhân ung thư vú thể ống xâm nhâp được được số hóa tiêu bản thông thường để xác định NCU theo ITBCC 2016 bằng phần mềm kính hiển vi ảo trên máy tính và đánh giá mối liên quan với một số đặc điểm GPB. Kết quả nghiên cứu: Tỷ lệ NCU đô cao trong nhóm ĐMH III là 35,1\%, cao hơn so với tỷ lệ NCU độ cao trong nhóm ĐMH I-II là 20,3\%. Tương tự, ở NC்U đô cao, UTV có di căn hạch là $41,8 \%$, cao hơn 2 lần so nhóm không có di cắn $(20,3 \%)$. Tỷ lệ NCU đô cao trong nhóm u có kích thước pT3 là 63,6\%, cao hơn tỷ lệ NCU độ cao trong nhóm u có kích thước pT1 \& pT2 là 25,8\%. Trong

\section{*Bệnh viện $K$}

Chịu trách nhiẹm chính: Nguyễn Văn Chủ

Email: chunv.nch@gmail.com

Ngày nhận bài:3.8.2021

Ngày phản biện khoa học: 1.10 .2021

Ngày duyệt bài: 12.10.2021

\author{
Nguyễn Văn Chủ*, Lê Thị Uyên**
}

nhóm có xâm nhập mạch bạch huyết, NCU độ cao là $35,6 \%$, cao hơn 1,5 lần so với nhóm không xâm nhâp mạch bạch huyết là 22,5\% ( $p<0,05)$. Kết luận: Có sự tương quan chặt chẽ giữa NCU độ cao với u kích thước lớn, di căn hạch nách, ĐMH cao, xâm nhập mạch bạch huyết.

Tư khóa: Nảy chồi u, Mô bệnh học, Ung thư vú, Giải phẫu bệnh số.

\section{SUMMARY \\ ASSESSMENT OF TUMOR BUDDING IN INVASIVE DUCTAL BREAST CARCINOMA BY DIGITAL PATHOLOGY}

In invasive breast carcinoma, tumor budding, highgrade correlates with tumor size, lymphavascular invasion, lymph node metastasis, and reduced 5-year survival of breast cancer patients. Purpose: (1) Determination of the tumor budding rates in invasive ductal breast carcinoma. (2) Commenting on some relationships between tumor budding levels and pathological characteristics. Methods: Tumor samples of 232 patients with invasive ductal breast cancer were digitized the conventional slides to identify Bds according to ITBCC 2016 by computer virtual microscope software and evaluated the relationship with some pathological features. Results: The rate of high-grade $\mathrm{Bd}$ of the grade III was $35.1 \%$, higher than high-grade Bd of the grade I and II of $20.3 \%$. Similarly, in high-grade Bd, breast cancer with lymph node metastasis was $41.8 \%$, twices higher than the group without metastasis (20.3\%). The rate of high- 